\title{
Time-Driven Activity-Based Cost Expansion Model
}

\author{
Lihui Zhao ${ }^{1}$ and Zihui Yang ${ }^{2,3}$ \\ ${ }^{1}$ Accountant, Department of Finance, Changsha Normal University, 9, Teli Road, Changsha, China. E-mail: \\ 464064245@qq.com \\ ${ }^{2}$ Professor, School of Management, Shandong University, 27, Shanda South Road, Ji'nan, China. E-mail: \\ 12498303@qq.com (corresponding author). \\ ${ }^{3}$ Professor, School of Economic \& Management, Changsha Normal University, 9, Teli Road, Changsha, China.
}

Project Management

Received September 14, 2021; revised December 3, 2021; accepted December 12, 2021

Available online December 27, 2021

\begin{abstract}
The classic Cost-Volume-Profit (CVP) model cannot meet the needs of accurate decision-making under the new cost structure, and the time-driven activity-based costing can accurately and timely respond to rising overhead costs through accurate identification of time-related resource consumption. By relaxing the constraints of the CVP model, based on the time-driven activity-based costing method, this paper reclassifies and divides the cost behavior, constructs an extended CVP analysis model, and uses the operating data of Hunan Gongsheng Fengsheng Equipment Manufacturing Co., Ltd (GSFS) to conduct the empirical analysis. The results show that the extended model is reliable and effective.
\end{abstract}

Keywords: Cost volume profit analysis, time-driven activity-based costing, model construction, empirical analysis.

Copyright $(\mathcal{C}$ Journal of Engineering, Project, and Production Management (EPPM-Journal).

DOI 10.32738/JEPPM-2022-0011

\section{Introduction}

China attaches great importance to the development of the industrial economy and the real economy and has established an overall strategic positioning for high-quality economic development. At the same time, the production method of the company has undergone a fundamental change. Cost reduction and efficiency increase have become the purpose of the company's production. The company has turned to provide customers with diverse and personalized products and services. This has led to the company's indirect costs in the product cost structure. To truly reflect the profitability and level of enterprises, the traditional CVP analysis method needs to be optimized and improved to provide more reference value for financial decision-making.

Schar and Okada (1972) proposed that the CVP analysis based on breakeven can scientifically judge the uncertainty tolerance of the enterprise's risk factors, thereby assisting the enterprise in making business decisions.

From a theoretical point of view, there are differences in the analysis results brought about by different theoretical, ideological guidance and different implementation methods, and there are also differences in the control of many indicators, including the cost for enterprises (Oyegoke et al., 2021), based on profit and loss, The CVP analysis of the balance point has an important position and function in many aspects such as the cost composition of the enterprise, the profit target and implementation strategy of the enterprise, the plan for the realization of the future value of the enterprise, etc. (Song et al., 2021). However, due to the limitations of the four assumptions based on the traditional CVP analysis, its theory and application need to be continuously updated and improved to avoid making wrong decision conclusions as much as possible (I Cabrera et al., 2020). The cash flow model obtained by deforming the CVP model can better provide corporate decision-makers with a reference for continuous operation (Xiang and $\mathrm{Li}$, 2007). It can not only analyze the investment cost, but also serve as an important reference for the development of corporate strategy (Zhao et al., 2020), or through the division of cost behaviors, the "Empirical Estimation Method" for mixed costs can be used based on this, the cost volume-profit model re-formulates the corporate work plan (Cooling et al., 2016).

From the perspective of industry application, combined with CVP analysis, the relevant factor indicators of specific models in the hotel industry are analyzed to confirm the practical significance and practical value of CVP analysis (Liao, 2020). In the circulation industry, we establish a jobbased CVP model and draw a feasibility conclusion based on the actual operating conditions of the enterprise (Song, 2020). CVP analysis helps the transportation industry to rationally control the cost and optimize profit margins (Wang et al., 2021) and use the net value method to control the cost of cargo transportation or product design of coastal enterprises (Gao, 2020). Based on the era of big data, Internet companies use the CVP model. The cost behavior is simulated and analyzed, and the marginal contribution is recalculated to make the profit predictable and guidable 
(Wang et al., 2019). The principal volume and profit are used in block holdings to analyze the agency costs of multiple holder structures such as different nationalities (Ibekwe, 2021). Air pollution emissions are also often applied to the cost control principle in the CVP model. A balanced model is constructed between short-term cost input and long-term ecological environmental cost to achieve the best (Astrom et al., 2019).

The results of CVP model optimization are also relatively rich. The terminal cost is designed as a linear model predictive controller, abstracted by replacing the 1/infinite norm stage cost with a convex Minkowski function, it is proved that the convex Minkowski is used to control the necessary and sufficient condition of the Lyapunov function, and the minimum convex set that satisfies the set contains is demonstrated. The optimal terminal cost (Danielson, 2021); BIM-based reconstruction project cost control method, using system dynamics or gray system theory to predict the relationship between the project cost, construct a cost-control dynamic model (Wang, 2019); based on the robustness of the error model, a stochastic model of average cost can also be constructed for control, so that the average cost is the most optimal under the conditions of total variational convergence and weak convergence (Kara et al., 2019).

The above research results have greatly enriched the research value of cost models and expanded the horizon of cost research. In the current era of rapid economic development and rapid globalization, the application of time-driven activity-based costing should be widely promoted and applied. However, there is little research literature on the optimization and verification of CVP models based on time-driven activity-based costing. This article introduces time-driven activity-based costing, redefines the cost behavior, optimizes the original CVP model, and conducts empirical analysis through case data, which has achieved good results.

\section{Theoretical Analysis and Extended Model Construction}

\subsection{Principles of Time-Driven Activity-Based Costing}

Time-Driver Activity-Based Costing (TDABC) is a cost calculation method that uses "time" to measure resource consumption. When using time-driven activity costing to allocate cost, two indicators need to be set, including:

(1) Operation cost per unit time (capacity cost rate): the ratio of the production cost to the total effective working time of employees. The effective working time here is the working time of employees or machinery and equipment after excluding idle working time, and the production capacity cost is the indirect cost.

(2) Unit operation time: the unit time the enterprise spends to complete a certain operation.

\subsection{Cost Composition Under Expanded Cost Behavior}

Time-driven activity-based costing is introduced into the CVP model, and the cost driver changes from simple machine hours, manual hours, product quantity, etc., to the cost of an activity, task, etc., as the traceability basis. In the expanded cost profile, the total cost of an enterprise is classified into variable cost, operating cost, and fixed cost.

\subsubsection{Variable Cost}

Assuming that the company produces $n$ types of products, $X_{i}$ is the output of the $i$-th product, and $V_{i}$ is the unit variable cost, the total variable cost $C_{v}$ of the company's products is expressed as shown in Eq. (1).

$$
C_{v}=\sum_{i=1}^{n} V_{i} X_{i}
$$

\subsubsection{Operating Cost}

Suppose that when producing $i$-product, there are $\mathrm{m}$ types of operations in the process, $C_{i j}$ is the unit time operating cost of the $j$-th type of operation of the $i$-product, $T_{i j}$ is the time-consuming unit of the $j$-th type of operation of the $i$ product, and $B_{i j}$ is the operation of the $j$-th operation of the $i$-product Times, the operating cost of all products is expressed as shown in Eq. (2).

$$
C_{w}=\sum_{i=1}^{n} \sum_{j=1}^{m} C_{i j} T_{i j} B_{i j}
$$

\subsubsection{Fixed Cost}

Fixed cost is a cost that has nothing to do with the amount of work performed by the enterprise, and it has nothing to do with the production and sales volume of the enterprise. It is set as a constant $F$.

\subsubsection{Total Cost Function.}

Based on the above analysis, the total cost is the sum of variable cost, operating cost, and fixed cost. The company's total cost function TC is expressed as shown in Eq. (3):

$$
T C=\sum_{i=1}^{n} V_{i} X_{i}+\sum_{j=1}^{m} C_{i j} T_{i j} B_{i j}+F
$$

\subsection{Construction of CVP Model Based on TDABC}

\subsubsection{Assumptions}

The assumptions for constructing TDABC's CVP model are as follows: the company's production and sales balance within a certain period; the total cost is composed of variable cost, operating cost, and fixed cost; the unit price of the company's products remains unchanged, and the sales revenue and production and sales are in a completely linear relationship; for a certain period, the production and sales structure of domestic products is stable.

\subsubsection{Constructing TDABC CVP Model}

Based on the assumptions, let the enterprise profit be $S T$, the unit price of product $i$ produced by the enterprise is $P_{i}$, the unit variable cost of product $i$ is $V_{i}$, and the production and sales volume of product $i$ is $X_{i}$, then the profit $S T$ is expressed as shown in Eq. (4):

$$
S T=\sum_{i=1}^{n}\left(P_{i}-V_{i}\right) X_{i}-\sum_{i=1}^{n} \sum_{j=1}^{m} C_{i j} T_{i j} B_{i j}-F
$$

The fixed cost $F$ is allocated according to the product category and output. For product $i$, its fixed cost is $F_{i}$. The profit function of a product is shown in Eq. (5):

$$
S T_{i}=\left(P_{i}-V_{i}\right) X_{i}-\sum_{j=1}^{m} C_{i j} T_{i j} B_{i j}-F_{i}
$$

When using Eq. (5) to analyze the guaranteed sales volume, that is, the profit $S T_{i}=0$, then the production and sales balance point of product $i$ is represented in Eq (6).

$$
X_{i}=\frac{\sum_{j=1}^{m} C_{i j} T_{i j} B_{i j}+F_{i}}{\left(P_{i}-V_{i}\right)}
$$

It can be seen from Eq. (6) that for product $i$, the costpreserving workload is no longer a point, but a curve composed of $m$ different combinations of operating links. Each point on the curve is the breakeven point of product $i$. There are four operation links, and the number of 
operations for each operation link is 0-3 times. The breakeven curve fitted by MATLAB is shown in Figure 1.

When multiple products are produced at the same time, the breakeven point will form a curved surface. The MATLAB fitting diagrams of the two products are shown in Fig. 2.
When the point formed by the combination of consumption work volume falls on the curved surface, the product reaches the breakeven; when the point formed by the combination of consumption work volume is above the surface, the product makes a profit; otherwise, the product loses money. If there are more than two products, the breakeven point will form a "hypersurface" graph.

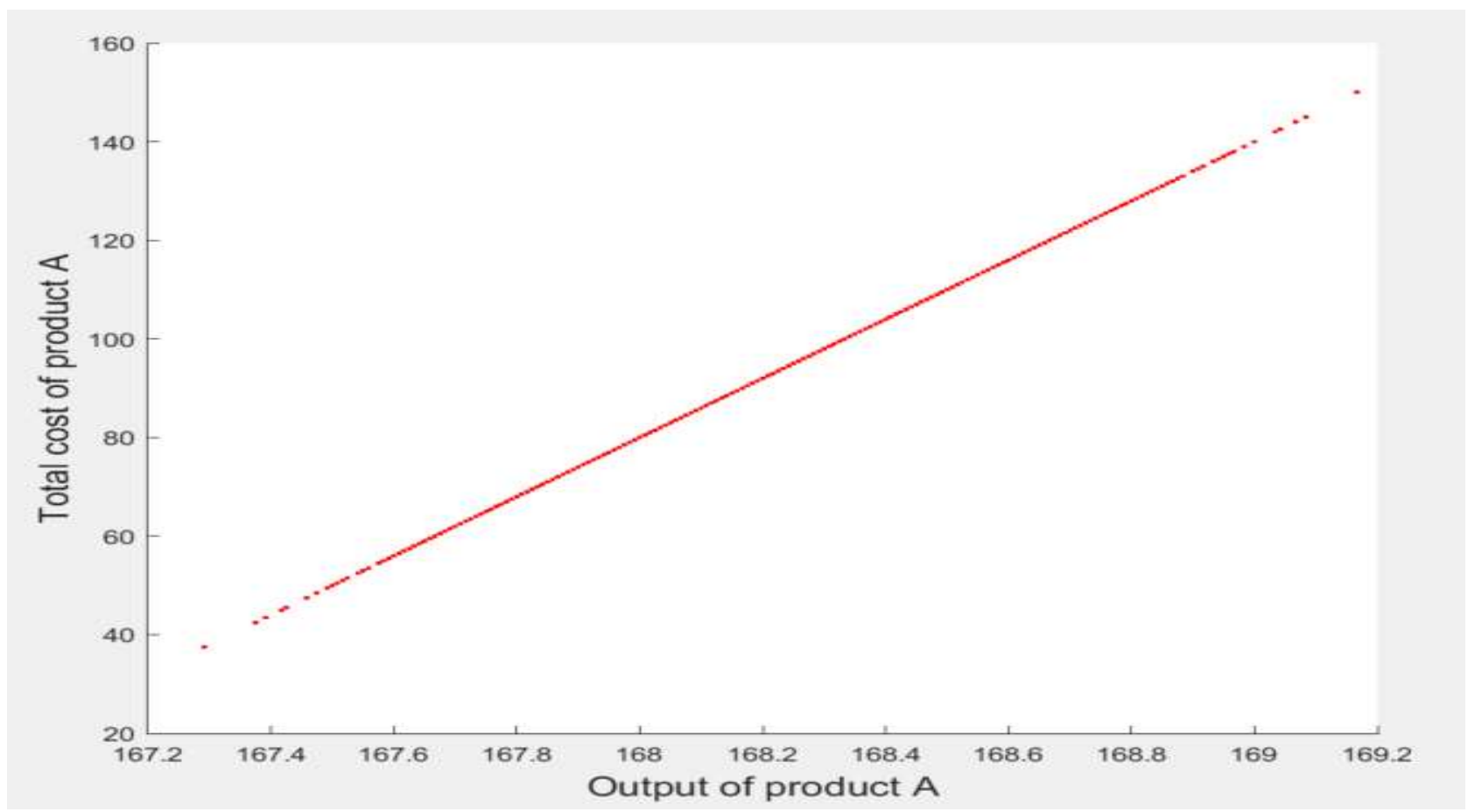

Fig.1. Break-even curve of a single product

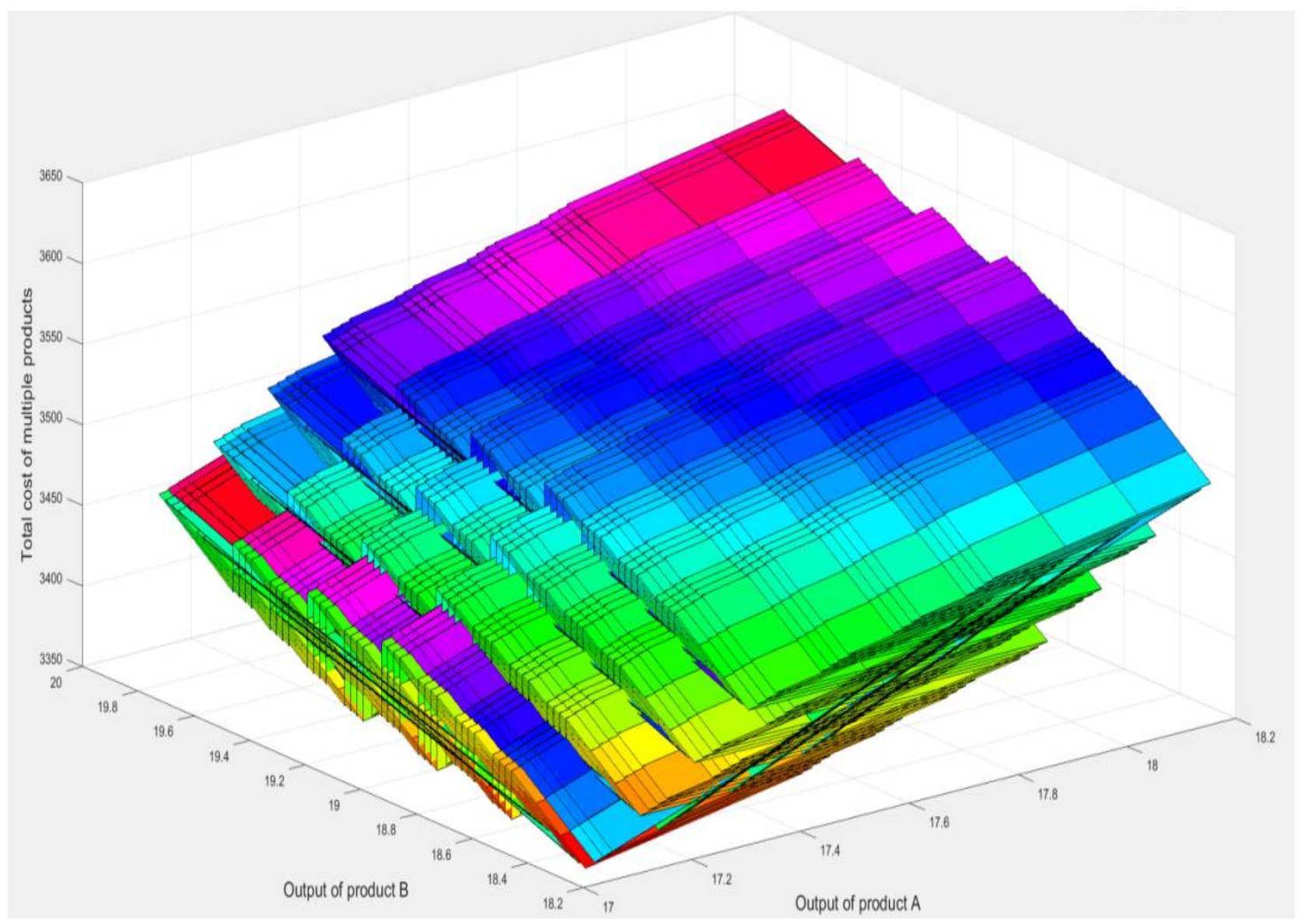

Fig.2. The breakeven diagram of the two products 


\section{Empirical Analysis}

Take the operating data of GSFS in November 2019 as an example, use the TDABC model to analyze the cost, volume, and profit.

\subsection{Empirical Analysis Based on the Traditional CVP Model}

The company's financial database will sort out the cost items incurred this month, divide the resource items according to their nature, and conduct a traditional CVP analysis. Departmental resource items and cost status are shown in Table 1.

The above resources are summarized according to the cost status, and the total variable cost is 938108.53 yuan, and the total fixed cost is 151118.97 yuan. A total of eight kinds of oil well products are produced, replaced by A-H. Variable cost and fixed cost are allocated according to the proportion of product sales cost, as shown in Table 2.
According to the traditional CVP model, the total profit result is obtained using Eq. (7).

$$
\begin{aligned}
\mathrm{ST} & =1344652.6-938107.6-151118.9 \\
& =255426.1 \quad \text { yuan }
\end{aligned}
$$

The profits of A-H are: 17091.49, 5261.45, 7756.59, $118760.84,10499.91,10204.19,1645.59$, and 84205.14.

Let $\mathrm{ST}=0$, then the sales volume at the critical point of profit and loss of A-H products are 5, 1, 6, 5, 1, 19, 4, and 6 .

\subsection{Empirical Analysis of CVP Model Based on TDABC}

Operating data shows that the direct costs incurred by various departments include 562,815.60 yuan for materials and $25,196.80$ yuan for labor, which are the variable costs of the departments. Indirect cost includes workshop personnel, wages, depreciation, machine material consumption, low-value consumables, utilities, social insurance, etc., as shown in Table 3.

\begin{tabular}{|c|c|c|}
\hline Resource project & Amount (yuan) & Cost behavior \\
\hline Direct material & 562815.60 & Variable \\
\hline Direct labor & 25196.80 & Variable \\
\hline Indirect labor & 64474.00 & Fixed \\
\hline Machine depreciation & 55651.47 & Fixed \\
\hline Machine repair and maintenance & 93363.00 & Fixed \\
\hline Social security charges & 91689.00 & Variable \\
\hline Low-value consumables & 29319.50 & Fixed \\
\hline Machine material consumption & 36.00 & Variable \\
\hline Water fee & 5079.93 & Variable \\
\hline Electricity bill & 26520.00 & Variable \\
\hline
\end{tabular}

Table 1. Division of departmental resource items and cost behavior

Table 2. Unit variable cost and fixed cost of A-H products

\begin{tabular}{cccccccc}
\hline \multirow{2}{*}{ Product } & \multirow{2}{*}{ Sales revenue } & \multirow{2}{*}{ Cost of sales } & \multirow{2}{*}{ Cost ratio } & Sales & $\begin{array}{c}\text { Variable product } \\
\text { cost }\end{array}$ & $\begin{array}{c}\text { Variable cost } \\
\text { subtotal }\end{array}$ & Fixed product \\
cost
\end{tabular}

Table 3. Classification table of resource projects of the Production Technology Department

\begin{tabular}{cc}
\hline Resource item classification & Amount (yuan) \\
\hline Indirect labor cost & 64474.00 \\
Depreciation expense & 55651.47 \\
Machine maintenance and operation & 148191.70 \\
Total & 268317.17 \\
\hline
\end{tabular}


According to the production process, the company divides the work into three links as machining, heat treatment, and assembly.

\subsubsection{Calculating Unit Operating Cost}

Indirect labor cost per unit time. The data in Table 3 show that the monthly indirect labor cost is 64474 yuan. There are 92 employees in the production department. The working days are 27 days. The working hours are 8.5 hours per day. The work efficiency is $80 \%$. The monthly production time is shown in Eq. (8):

$$
8.5 \times 92 \times 27 \times 80 \%=16891.2 \text { hours }
$$

The indirect labor unit time operation cost is calculated using Eq. (9).

$$
\frac{64474}{16891.2}=3.82 \text { yuan/hour }
$$

The cost of machine depreciation is allocated to the three operations of machining, heat treatment, and assembly, all of which use professional equipment. The depreciation cost of the machine in the production workshop this month is 55,651.47 yuan. The data of working hours required for the production of each product is shown in Table 4.

The data shows that the theoretical working time of the machine in that month is $1,3188.3$ hours, and the effective operation rate is $90 \%$. Given that the effective utilization rate of GSFS company's machine is $90 \%$, the operating cost per unit time of machine depreciation is represented in Eq. (10).

$$
\frac{55651.47}{13188.3 * 90 \%}=4.69 \text { yuan } / \text { hour }
$$

Machine maintenance and operating costs mainly occur in machining equipment, heat treatment equipment, and assembly line equipment. Therefore, machine repair and maintenance costs are allocated to the three operations of machining, heat treatment, and assembly. The machine repair and maintenance cost for the month was 148191.7 yuan. The unit time operating cost of machine repair and maintenance is shown in Eq. (11).

$$
\frac{148191.7}{13188.3 * 90 \%}=12.49 \text { yuan/hour }
$$

\subsubsection{Calculating the Cost Driver Rate}

The cost driver rate is the product of the unit time operation cost (capacity cost rate) and the unit operation time. According to the data, the indirect labor time for each product is shown in Table 5. Moreover, the driver rate of the indirect labor cost of each product is shown in Table 6 .

In November 2019, the depreciation cost of the machine was 55,651.47 yuan, and the maintenance and operating cost of the machine was 148191.70 yuan. According to the timeconsuming and utilization rate of the machine in Table 4 and the sales volume in Table 2, that the machining time is 9820.5 hours, the heat treatment time is 403.3 hours, and the assembly time is 1645.7 hours. These two items are related to the operation of machinery and equipment, and the operating time of the machinery is the operating cost driver. The unit time operating costs of depreciation and maintenance are 4.69 yuan and 12.49 yuan, respectively. The driver rates of machine depreciation, machine maintenance, and operating cost are obtained, as shown in Table 7.

\subsubsection{Assignment of Operating Cost}

Indirect labor cost allocation. According to the sales volume in Table 2, the costs of machining, heat treatment, and assembly are allocated to 106 products. The calculation formula of the indirect labor cost of each product is the cost driver rate of the product $\times$ the output, and the results of the cost allocation of the operation are shown in Table 8 .

Table 4. Time-consuming of each product unit operation

Unit: hours

\begin{tabular}{ccccc}
\hline Product & Machining & Heat treatment & Assembly & Unit total time \\
\hline A & 43.7 & 3.2 & 0 & 46.9 \\
B & 93.3 & 7.2 & 1.5 & 102 \\
C & 43.8 & 3.2 & 1.5 & 48.5 \\
D & 93.4 & 7.2 & 18.5 & 119.1 \\
E & 431.2 & 7.2 & 18.5 & 456.9 \\
F & 93.5 & 0.5 & 13.5 & 107.5 \\
G & 4.0 & 0.2 & 0.5 & 4.7 \\
H & 292.4 & 13.2 & 68.5 & 374.1 \\
\hline
\end{tabular}

Table 5. Indirect labor time for each unit of product

\begin{tabular}{ccccc}
\hline Product & Machining & Heat treatment & Assembly & Total \\
\hline A & 34.6 & 2.5 & 0 & 37.1 \\
B & 417.9 & 32 & 6.6 & 456.5 \\
C & 73.4 & 5.3 & 2.5 & 81.2 \\
D & 73.7 & 5.7 & 14.5 & 93.9 \\
E & 5787.7 & 96.1 & 246.6 & 6130.4 \\
F & 38 & 0.2 & 5.5 & 43.7 \\
G & 4.4 & 0.3 & 0.5 & 5.2 \\
H & 261.4 & 11.7 & 60.9 & 334 \\
\hline
\end{tabular}


Table 6. Indirect labor cost driver rate of each product Unit: hours

\begin{tabular}{ccccc}
\hline Product & Machining & Heat treatment & Assembly & Total \\
\hline A & 132.2 & 9.6 & 0 & 25.2 \\
B & 1596.4 & 122.2 & 9.6 & 1743.8 \\
C & 280.4 & 20.2 & 55.4 & 310.2 \\
D & 281.5 & 21.8 & 942 & 358.7 \\
E & 22109 & 367.1 & 21 & 23418.1 \\
F & 145.2 & 0.8 & 1.9 & 166.9 \\
G & 16.8 & 1.1 & 232.6 & 19.9 \\
H & 998.5 & 44.7 & 1275.9
\end{tabular}

Table 7. Motivation rates of machine depreciation and maintenance costs for each unit product

\begin{tabular}{ccccccc}
\hline Product & Machining & $\begin{array}{c}\text { Heat } \\
\text { treatment }\end{array}$ & Assembly & Unit total time & $\begin{array}{c}\text { Depreciation driver } \\
\text { rate }\end{array}$ & Repair motivation rate \\
\hline A & 39.3 & 2.9 & 0 & 42.2 & 197.9 & 527.1 \\
B & 84 & 6.4 & 1.4 & 91.8 & 430.5 & 1146.6 \\
C & 39.4 & 2.9 & 1.4 & 43.7 & 205 & 545.8 \\
D & 84.1 & 6.5 & 16.6 & 107.2 & 502.8 & 1338.9 \\
E & 388.1 & 6.4 & 16.7 & 411.2 & 1928.5 & 5135.9 \\
F & 84.1 & 0.5 & 12.2 & 96.8 & 454.0 & 1209.0 \\
G & 3.5 & 0.2 & 0.5 & 4.2 & 19.7 & 52.5 \\
H & 263.1 & 11.9 & 61.7 & 336.7 & 1579.1 & 4205.4 \\
\hline
\end{tabular}

Table 8. Indirect labor cost allocation for each product

\begin{tabular}{cccccc}
\hline Product & Yield & Machining & Thermal processing & Assembly & Activity cost subtotal \\
\hline A & 17 & 2245.16 & 162.99 & 0 & 2408.2 \\
B & 3 & 4785.37 & 366.81 & 75.96 & 5228.1 \\
C & 8 & 2242.11 & 162.99 & 75.96 & 2481.1 \\
D & 17 & 4785.37 & 366.81 & 941.27 & 6093.5 \\
E & 1 & 22091.65 & 366.81 & 941.27 & 23399.7 \\
F & 33 & 4785.37 & 24.81 & 687.44 & 5497.6 \\
G & 12 & 202.68 & 14.12 & 24.81 & 241.6 \\
H & 15 & 14965.31 & 671.41 & 3487.21 & 19123.9 \\
Total & 106 & 56103.02 & 2136.75 & 6233.92 & 64474 \\
\hline
\end{tabular}

In the above tables, the cost apportionment of each operation link can be obtained by apportioning the cost according to the proportion in the cost driver table.

For machine depreciation cost allocation, similar to the indirect labor cost allocation, the calculation formula for the machine depreciation cost of each product is:

\section{The Product's Depreciation Cost Driver Rate $\times$ Output}

The result of the cost allocation is shown in Table 9.

Regarding machine maintenance and operating cost allocation, in the same way, the results of machine maintenance and operating cost allocation for each product are obtained, as shown in Table 10.
According to the results of the above calculations, the production and technical department of the company's production and the technical department have compiled a summary table of the cost of each product in the current month as shown in Table 11 and Table 12.

The company's data shows that there is no attributable fixed cost for this department in the current month, that is, $F=0$. Based on the matching ratio of income and expenses and the principle of cost-effectiveness, the variable cost is allocated through the proportion of product sales cost, and the sales proportion is calculated according to the proportion of sales cost; the total variable cost per unit is the unit of each type of product. The sum of the cost, the results are shown in Table 13. 
Table 9. Cost allocation for machine depreciation operations of various products

\begin{tabular}{cccccc}
\hline Product & Yield & Machining & Thermal processing & Assembly & Activity cost subtotal \\
\hline A & 17 & 3131.4 & 231.1 & 0 & 3362.5 \\
B & 3 & 1181.1 & 91.4 & 19.7 & 1292.2 \\
C & 8 & 1477.3 & 108.7 & 52.5 & 1638.5 \\
D & 17 & 6701 & 517.9 & 1330.6 & 8549.5 \\
E & 1 & 1819 & 30.5 & 78.3 & 1927.8 \\
F & 33 & 13023.3 & 77.3 & 1887 & 14987.6 \\
G & 12 & 202.5 & 11.2 & 28.1 & 241.8 \\
H & 15 & 18504.3 & 836.6 & 4337.8 & 23678.7 \\
Total & 106 & 46039.9 & 1904.7 & 7734 & $55651.47^{* *}$ \\
\hline$* *$ The calculation result is 55678.6, and the error of $0.06 \%$ is caused by rounding.
\end{tabular}

** The calculation result is 55678.6, and the error of $0.06 \%$ is caused by rounding.

Table 10. Machine maintenance and operation cost allocation for each product

\begin{tabular}{cccccc}
\hline Product & Yield & Machining & Thermal processing & Assembly & Activity cost subtotal \\
\hline A & 17 & 8344.6 & 615.8 & 0 & 8960.4 \\
B & 3 & 3147.5 & 243.6 & 52.5 & 3443.6 \\
C & 8 & 3936.8 & 289.8 & 139.9 & 4366.5 \\
D & 17 & 17857 & 1380.1 & 3545.9 & 22783 \\
E & 1 & 4847.4 & 81.2 & 208.6 & 5137.2 \\
F & 33 & 34704.7 & 206.1 & 5028.5 & 39939.3 \\
G & 12 & 539.6 & 30 & 74.9 & 644.5 \\
H & 15 & 49310.5 & 2229.5 & 11559.5 & 63099.5 \\
Total & 106 & 122688.1 & 5076.1 & 20609.8 & $148191.7^{* *}$ \\
\hline
\end{tabular}

** The calculation result is 148374 , and the error of $0.12 \%$ is caused by rounding

Table 11. Summary of calculating activity costs by cost category

\begin{tabular}{ccccc}
\hline Operation & Machining & Heat treatment & Assembly & Subtotal \\
\hline Indirect labor & 56103.02 & 2136.75 & 6233.92 & 64474 \\
Machine depreciation & 46039.9 & 1904.7 & 7734 & 55651.47 \\
Machine maintenance and operation & 122688.1 & 5076.1 & 20609.8 & 148191.7 \\
Total & 224831.02 & 9117.55 & 34577.72 & 268317.2 \\
\hline
\end{tabular}

Table 12. Summary of operating costs of each product

Unit: hours

\begin{tabular}{ccccc}
\hline Product & Machining & Heat treatment & Assembly & Total cost \\
\hline A & 13721.16 & 1009.89 & 0 & 14731.1 \\
B & 9113.97 & 701.81 & 148.16 & 9963.9 \\
C & 7656.21 & 561.49 & 268.36 & 8486.1 \\
D & 29343.37 & 2264.81 & 5817.77 & 37426 \\
E & 28758.05 & 478.51 & 1228.17 & 30464.7 \\
F & 52513.37 & 308.21 & 7602.94 & 60424.5 \\
G & 944.78 & 55.32 & 127.81 & 1127.9 \\
H & 82780.11 & 3737.51 & 19384.51 & 105902.1 \\
Total & 224831.02 & 9117.55 & 34577.72 & 268317.2 \\
\hline
\end{tabular}

Journal of Engineering, Project, and Production Management, 2022, 12(2), 116-125 
Table 13. Variable cost per product unit

\begin{tabular}{cccccccc}
\hline Product & $\begin{array}{c}\text { Sales } \\
\text { revenue }\end{array}$ & Cost of sales & $\begin{array}{c}\text { Percentage } \\
\text { of sales }\end{array}$ & Sales & $\begin{array}{c}\text { Unit } \\
\text { variable cost }\end{array}$ & $\begin{array}{c}\text { Variable cost } \\
\text { subtotal }\end{array}$ & Operating cost \\
\hline A & 74420.37 & 37776.84 & $5.26 \%$ & 17 & 2522.60 & 42884.2 & 14731.1 \\
B & 23725.81 & 12167.08 & $1.70 \%$ & 3 & 4604.01 & 13812.0 & 9963.9 \\
C & 34362.09 & 17531.68 & $2.44 \%$ & 8 & 2487.74 & 19901.9 & 8486.1 \\
D & 555747.07 & 287951.85 & $40.12 \%$ & 17 & 19228.37 & 326882.3 & 37426 \\
E & 44228.13 & 22225.19 & $3.10 \%$ & 1 & 25229.99 & 25230.0 & 30464.7 \\
F & 111792.79 & 66941.79 & $9.33 \%$ & 33 & 2302.79 & 75992.1 & 60424.5 \\
G & 7165.28 & 3637.20 & $0.51 \%$ & 12 & 344.08 & 4129.0 & 1127.9 \\
H & 493211.10 & 269514.26 & $37.55 \%$ & 15 & 20396.80 & 305952.0 & 105902.1 \\
Total & 1344652.64 & 717745.89 & $100.00 \%$ & 106 & - & 814783.5 & 268317.2 \\
\hline
\end{tabular}

\subsubsection{Testing the TDABC Empirical Result}

Through the above analysis and calculation, substituting into Eq. (4), the expression of the total profit can be obtained using Eq. (12).

$$
\begin{aligned}
S T & =1344652.6-814783.5-256758.1 \\
& =273111.1 \quad \text { yuan }
\end{aligned}
$$

Assuming that the product operating cost remains unchanged, that is, there is no correlation between the sales volume and the volume of operations, let $S T_{i}=0$, and substitute in Eq. (6), then the sales volume of A-H products at the breakeven points are 10, 1, 4, 3, 0, 57, 4, 9 units (the sales volume at the breakeven point has been rounded up.).

Assuming that the gross profit contributed by the product remains unchanged, and the workload of machining, heat treatment, and assembly of three types of costs such as indirect labor, machine depreciation, and machine maintenance and operation are set as matrix $B$ in Eq. (13).

$$
B=\left[\begin{array}{lll}
b_{11} & b_{12} & b_{13} \\
b_{21} & b_{22} & b_{23} \\
b_{31} & b_{32} & b_{33}
\end{array}\right]
$$

Take the product A as an example, let $S T_{A}=0$, because the assembly operation is zero, so the third column of the matrix is all 0 , then, the activity-based cost is calculated as follows in Eq. (14).

$$
\begin{array}{r}
C_{w}=3.82 \times 43.7 \times b_{11}+3.82 \times 3.2 \times b_{12} \\
+4.69 \times 43.7 \times b_{21}+4.69 \times 3.2 \times b_{22} \\
+12.49 \times 43.7 \times b_{31}+12.49 \times 3.2 \times b_{32} \\
=36643.5 \text { yuan }
\end{array}
$$

As a result, the cost-preservation work volume of $\mathrm{A}$ product is no longer a specific constant term. By calculating the simplified formula, the coordinates of the six vertices can be obtained:

$$
[219.5,0,0,0,0,0] \text {; }
$$

$$
\begin{aligned}
& {[2997.7,0,0,0,0,0] ;} \\
& {[178.8,0,0,0,0,0] ;} \\
& {[2441.6,0,0,0,0,0] ;} \\
& {[67.1,0,0,0,0,0] ;} \\
& {[916.8,0,0,0,0,0] .}
\end{aligned}
$$

Through the combination of vertex coordinates, a "hyper" surface can be constructed. At this time, the costpreserving workload of product $\mathrm{A}$ is the combination of the workload consumed by the product in the three operations of machining, heat treatment, and assembly. For product A, there are three relationships between the workload combination of machinings, such as heat treatment, assembly and the "super" surface.

(1) When the point formed by the combination of consumption workload just falls on the hypersurface, the product reaches a breakeven;

(2) When the point formed by the combination of the consumption workload is outside the convex surface or inside the concave surface of the hypersurface, the product is profitable;

(3) When the point formed by the combination of the consumed workload is inside the convex surface or outside the concave surface of the hypersurface, the product is at a loss.

In the same way, B-H products can also perform TDABC cost-guaranteed workload analysis and get relevant conclusions. Based on this conclusion, profit analysis and product sensitivity analysis can also be conducted for product operations.

\section{Conclusions}

Through the use of traditional CVP analysis and empirical analysis of the CVP model based on time-driven activity costing on actual business data, the product profit comparison chart and the guaranteed sales volume comparison chart are obtained, as shown in Fig. 3 and 4. 


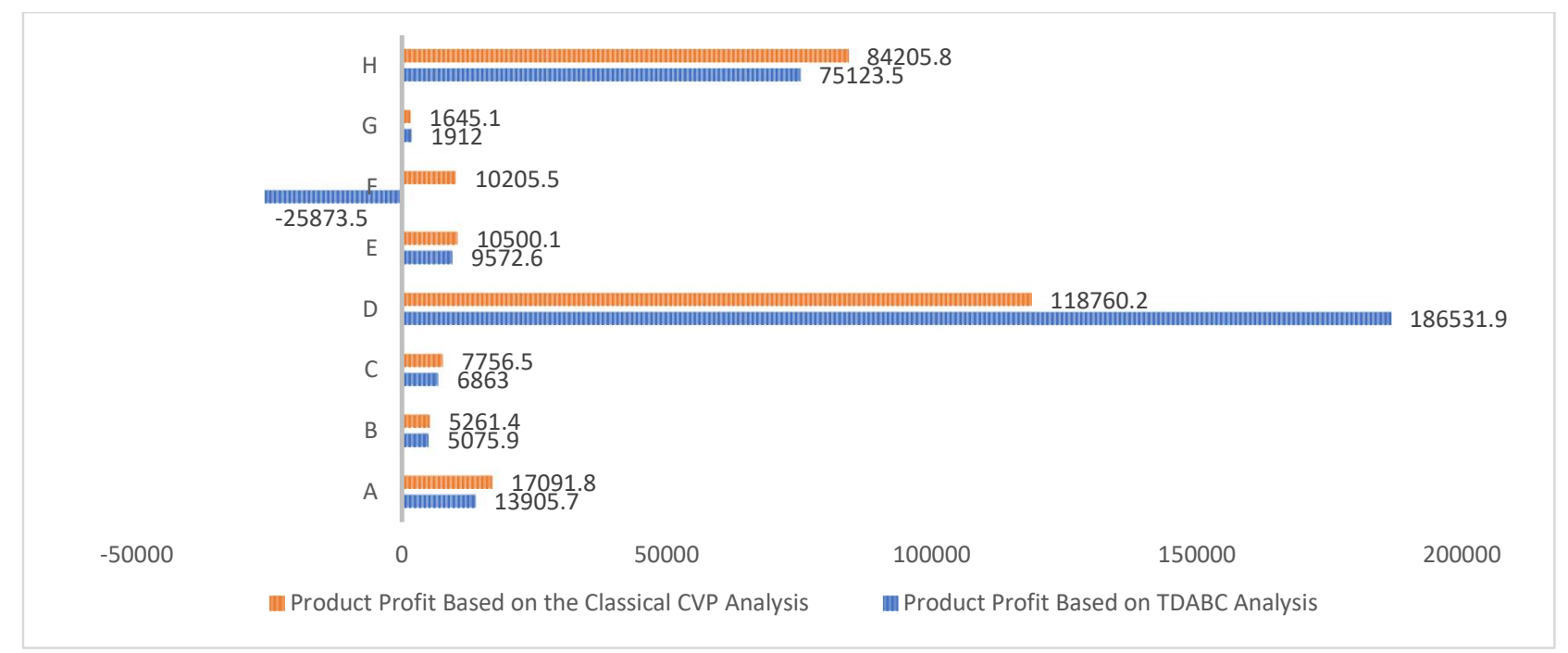

Fig.3. Profit comparison chart of various products

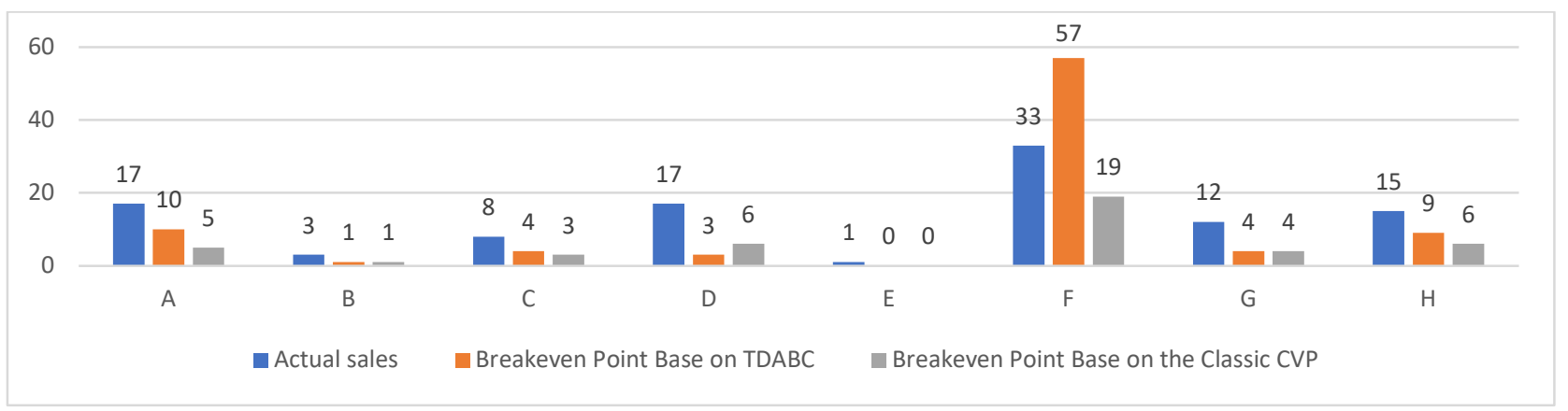

Fig.4. Comparison of guaranteed sales volume of various products

Through the comparative analysis of the profit and the guaranteed sales volume of each product of the two CVP models, the following conclusions are drawn:

(1) In terms of product profit, the TDABC analysis method more clearly reflects the profitability of each product. For the traditional CVP model, the applicable condition is that the product variety structure is stable. Once the enterprise adjusts the product structure, it is easy to cause a large error between the product cost information and the actual situation, resulting in decision-making errors. Based on the CVP analysis of TDABC, the allocation of cost is more accurate, and the "profit illusion" in the revenue generation of each product can be accurately identified, so that the product structure can be adjusted and optimized quickly, and the decision-making correction and adjustment can be completed.

(2) As far as the analysis of breakeven sales volume is concerned, based on TDABC's CVP analysis, it can help companies determine a more accurate breakeven sales volume compared to traditional CVP analysis, which can provide more information for the company's overall strategic decision-making and product production and operation strategies. Valuable and reliable cost information.

(3) Based on TDABC's CVP analysis, it is more suitable for social development and market requirements. With the rapid development of current technology, the increase in the added value of products and enhanced serviceability has led to an increasing proportion of the indirect cost of products. Through the analysis of cost behavior, the cost is re-divided, requiring cost analysis to identify the driving factor divided by output. Other factors include time, motivation, workload, etc. The CVP analysis based on TDABC is a cost analysis based on more influencing factors. Therefore, companies can improve the accuracy of cost allocation to a greater extent. At the same time, cost analysis based on time motivation can better compare industry data horizontally, which is more conducive for companies to fully understand the current situation of the industry and recognize the market situation, to know the industry well, accurately interpret, and grasp the initiative to develop for the better.

In addition, the CVP optimization model based on time-driven activity-based costing can analyze the CVP analysis of a single product or product type for a multifarity structured enterprise, which can better reflect the detailed situation of product consumption resources, which is important for managers to identify idle resources, optimizing resource allocation, and improving economic efficiency have important reference values.

Based on TDABC, this paper re-divisions the cost behavior, improves the traditional CVP model, and uses real business data for empirical analysis, and draws more reliable conclusions.

At the same time, under the conditions of a perfectly competitive market, there are increasingly homogeneous products. To gain market recognition, product differences must be highlighted. At this time, there will be a non-linear correlation between product sales and prices. The CVP analysis model based on TDABC is of multiple assumptions and can solve nonlinear correlations. Therefore, considering the problem of nonlinear CVP optimization is the direction of future research. 


\section{Acknowledgments}

This work was supported by Hunan Educational Science "Thirteenth Five-Year" Research Financial Construction Project (CJ193920), and Changsha Normal University "Business Administration" Funding for key construction disciplines.

\section{Reference}

Astrom, S., Kiesewetter, G., and Schopp, W., et al. (2019). Investment perspectives on costs for air pollution control affect the optimal use of emission control measures. Clean Technologies and Environmental Policy, 21(03), 695-705.

Cooling, N. A., Barnes, E., and Almyahi, F., et al. (2016). A low-cost mixed fullerene acceptor blend for printed electronics. Journal of Materials Chemistry A, 26(4), 10274-10281.

Danielson, C. (2021). Terminal-cost design for model predictive control with linear stage-costs: A settheoretic method. Optimal Control Applications \& Methods, 42(4), 943-964.

Gao, S. H. (2020). Cost Control Method for Goods Transportation of Coastal Enterprises Based on Earned Value Method. Journal of Coastal Research, 103, 674-677.

I Cabrera, L. U. and JV Pérez, L. O. (2020). Bank branch performance and cost efficiency: A stochastic frontier panel data approach. International Journal of Finance \& Economics, 26(4), 5850-5863.

Ibekwe, I. (2021). Block holding and agency cost: evidence from Nigeria[J/OL]. International Journal of Emerging Markets, 06.

Kara, A. D., Raginsky, M., and Yuksel, S. (2019). Robustness to Incorrect Models in Average-Cost Optimal Stochastic Control. 2019 IEEE 58TH Conference on Decision and Control (CDC), 79707975 .

Liao, B. B. (2020). Practice and exploration of constructing product cost volume profit model in $\mathrm{C}$ Company. Aeronautical Finance and Accounting, 2(05), 50-54+61.

Oyegoke, A. S., Powell, R., and Ajayi, S., et al. (2021). Dynamic Control and Management of Construction Engineering Cost [J/OL]. Journal of Financial Management of Property and Construction, 26(02).

Schar, J. F. and Okada, C. (1972). Social and economic issues of consumer cooperatives [Die soziale und wirtschaftliche Aufgabe der Konsumgenossensch-aften 1910]. Konan Business Research, 12(2), 171-186.
Song, L. (2020). Application of CVP Analysis to Decision Making of Railway Transport Products. China Railway, 04, 23-30.

Song, S., McCann, R. A., and Jang, G. (2021). Cost-Based Adaptive Droop Control Strategy for VSC-MTDC system. IEEE Transactions on Power Systems, 01, 659-669.

Wang, Y. (2019). BIM-based Method for the Cost Control of Civil Building Reconstruction after Earthquakes. China Earthquake Engineering Journal, 41(01), 233-238.

Wang, Y. T., Feng, Y., Gao, and R. C., et al. (2019). Cost volume profit Analysis and Prediction of Shared Bicycles Under the New Retail Trend. Management and Administration, 05, 44-47.

Wang, G. X., Wu, J., and Ma, X. Q. (2021). A guaranteed cost strategy for speed-limit control of vehicles based on map information. Proceedings of The Institution of Mechanical Engineers Part D-Journal of Automobile Engineering, 235(12), 3127-3137.

Xiang, E. W. and Li, Q. (2007). Application of cash flow model based on the deformation of cost volume profit model in enterprise decision-making. China Management Informationization (Accounting Edition), 10(07), 75-76.

Zhao, H. R., Lu, H., and Zhang, S. Y., et al. (2020). Value Measurement and Economic Evaluation of Energy Storage System Considering Extremality. Journal of Technology Economics, 39(10), 19-26+53.

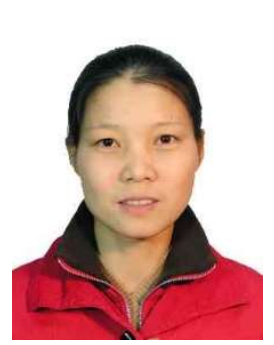

Lihui Zhao, an accountant in the Finance Department of Changsha Normal University, has been committed to the research on financial management for more than 20 years and has published seven papers, presided over or participated in three provincial research projects.

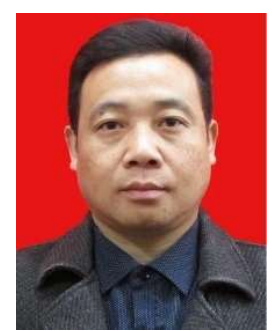

Zihui Yang, born in 1972 in Changde, China, is a professor at the school of economics and management of Changsha Normal University. He has published more than 40 papers and presided over eight topics. His research direction is applied economics. 